\title{
La ciudad como proceso de comunicación
}

Javier Esteinou Madrid

Departamento de Educación y Comunicación de la UAM-Xochimilco

\section{Antecedentes}

LA TRADICIÓN de estudio de los procesos de comunicación en América Latina nos ha llevado a privilegiar primero el análisis de los emisores, posteriormente la observación de los mensajes o discursos, y finalmente, en los últimos años se ha considerado el examen de la situación de los receptores. Dentro de este contexto de prioridades analíticas hemos centrado mayoritariamente el examen de los procesos de comunicación sobre los medios de información masiva y sus derivados simbólicos; y con ello hemos olvidado o desconocido que en nuestras vidas cotidianas existen otras grandes fuerzas comunicativas, tan o más importantes, que los canales electrónicos de difusión colectiva que determinan constantemente nuestra comunicación y nos imponen, para bien o para mal, un estilo de vida y de humanización.

Así, dentro de esta tradición de reflexión hemos desconocido que la ciudad y sus derivados urbanos son una poderosísima fuerza que actúa sobre nuestro acontecer diario influyendo en nuestra forma de pensar, sentir, actuar, imaginar, vestir, trabajar, descansar, vincularnos con la naturaleza, divertirnos, etc., es decir, sobre nuestra forma y calidad de vida. De esta forma, la ciudad aparece como algo más que un simple espacio territorial que cobija a los ciudadanos dentro de sus fronteras urbanas.

Bajo esta perspectiva, podemos decir que:

La ciudad da qué sentir y loque sentimos es una cierta organización del espacio, espacios llenos o vacíos (...) El aspecto formal es su manera de expresión, la forma como se nos 
manifiesta está intrínsecamente unida a la materialidad del lugar. Pero sin duda todos estos espacios dan qué sentir gracias a nuestra corporalidad. la simbólica de la ciudad está íntimamente ligada a nuestro cuerpo. El cuerpo es "lugar" primordial de comunicación, de apertura al mundo, a los otros, a la historia, y a la cultura. Gracias al cuerpo el sentido de la ciudad se nos descubre al transitar por ésta, que no es otra cosa que la apropiación del código urbano para producir en él una enunciación (Rubio Angulo, 1993: 15 y 16).

Es por ello, que siendo que al final del siglo XX el principal espacio donde se concentra la población de América Latina y del resto del Planeta es en las ciudades, ya que uno de cada cuatro latinoamericanos vive en las urbes y ya no en el campo; ${ }^{1}$ ahora estamos obligados a retomar la realidad comunicación-ciudad como una prioridad para analizar y transformar dentro del ámbito de las políticas nacionales de comunicación: Ante un continente eminentemente urbano, debemos de desarrollar prioritariamente proyectos de comunicación y cultura urbanos.

\section{Tendencias comunicativas en la evolución de las ciudades}

Frente al fenómeno de comunicativo de concentración urbana, debemos expresar que debido a que dicha realidad ha sido abandonada notablemente por la reflexión latinoamericana en el campo de la información y la cultura, actualmente no se puede presentar una teoría avanzada o madura sobre la relación que se establece entre comunicación-ciudad; sino sólo una visión aproximada al problema. Es decir, no obstante que se han desarrollado cuatro reuniones sobre comunicación y ciudad impulsadas por al Organización de las Naciones Unidas para la Educación, la Ciencia y la Cultura (UNESCO), ${ }^{2}$ en América Latina a mitad de la década de los

1 Declaración de Rosario por el derecho a la ciudad (1992): Conclusiones del Seminario Internacional sobre Comunicación y Ciudad. República de Argentina, Rosario, Provincia đe Santa Fe: Fundación Solidaridad, 24 al 26 de agosto, p. 1.

2 Las reuniones realizadas en América Latina por la UNESCO son las siguientes: Comunicación y ciudad (1992): Rosario, Provincia de Santa Fe, República de Argentina, del 24 al 26 de agosto; Comunicación y calidad de vida en la ciudad (1993):, Universidad de Azuay/Instituto de Estudios de Régimen Seccional del Ecuador,IERSE. Municipio de Cuenca, Ecuador, del 6 al 8 de julio; Comunicación y ciudad: hacia una mejor calidad de vida urbana (1994): Facultad Politécnica de la Unive rsidad Nacional de Asunción. Asunción, Paraguay, del 21 al 23 de septiembre, y Comunicación y ciudad, Universidad Pontificia Bolivariana / Alcaldía de Medellín. Medellín, Colombia, del 15 al 17 de junio. 
noventa sólo podemos decir que nos encontramos en una fase embrionaria de estudios y comprensión sobre dicha realidad.

Es por esto, que a continuación presentamos los siguientes diez elementos generales que pensamos que nos pueden permitir introducirnos en la comprensión del fenómeno comunicación-ciudad en los tiempos de la modernidad latinoamericana: 1) El capital como arquitecto de las ciudades latinoamericanas, 2) La concentración de las comunicaciones, 3) La deshumanización de las urbes, 4) La comunicación urbana como negocio, 5) El surgimiento de la video-vida, 6) El derrumbe de las relaciones humanas, 7) La tecnificación de la comunicación, 8) La video comunicación, 9) La reproducción espiritual urbana vía los medios de comunicación y 10) El hombre ausente del estudio de los̀ procesos de comunicación urbanos.

\section{El capital como arquitecto de las ciudades latinoamericanas}

El diseño y construcción de las grandes y modernas ciudades latinoamericanas ha sido realizado fundamentalmente con base en la operatividad de las dinámicas económicas de acumulación de capital, pero nunca han sido planificadas centralmente como espacios de comunicación humana. Los criterios de funcionalidad económica al más bajo costo, no sólo han producido fenómenos de carácter financiero, político, social, demográfico, ecológico, energético, etcétera, en las urbes, sino también comunicativo, desde el momento en que la construcción de los entornos físicos edificados no sólo tiene un impacto material sobre los seres humanos que los habitan, sino también fuertemente cultural.

Es decir, los contextos espaciales elaborados no solamente nos determinan de manera económica y social, sino también mental, desde el momento en que los individuos nos relacionamos, pensamos, sentimos, imaginamos, movemos, amamos, interactuamos, etcétera, humanamente dentro de estas coberturas físicas. Por lo tanto, en gran parte la naturaleza y calidad de pensamientos, imaginación, esparcimiento, emotividades, desplazamientos, interrelaciones, etcétera, que producimos en las urbes, depende, directa o indirectamente, de la forma como están construidas las ciudades. En este sentido, lo urbano puede entenderse como 
un "conglomerado humano en medio del cual funciona de manera permanente un complejo sistema de comunicación e información". 3

\section{La concentración de las comunicaciones}

Debido a la forma centralizada como han evolucionado las concentraciones humanas en América Latina, la ciudad se ha convertido en un espacio muy privilegiado para el cruce y concentración de las comunicaciones tecnológicas. Así observamos por ejemplo, que en las metrópolis se encuentran reunidos el mayor porcentaje de teléfonos, faxes, telecomunicaciones, fibras ópticas, terminales satelitales, bases de datos, redes de computadoras, conexiones coaxiales, medios interactivos, etcétera.

Esta realidad ha convertido a las zonas urbanas de Latinoamérica en territorios de mayor calidad de comunicación tecnológico-instrumental que otras regiones rurales de nuestros países. Es decir, por la mayor concentración de redes de información las ciudades se han transformado en grandes y estratégicos centros nerviosos para el funcionamiento de nuestras sociedades.

\section{La deshumanización de las urbes}

Al no ser diseñados los entornos urbanos latinoamericanos para satisfacer los requisitos de una calidad de vida superior, sino de consolidación de los procesos industriales para fortalecer el flujo de macro concentración de capital, a costa de lo que sea; ha sido mayoritariamente la evolución de la acumulación material lo que ha definido la naturaleza de nuestras ciudades. Así, en el terreno espiritual de las urbes hemos observado el surgimiento de un paisaje urbano-comunicativo cada vezmás inhóspito e inhumano, pues los espacios de vida y convivencia son planeados básicamente para generar productividad rápida, abundante, eficiente y competitiva; y no para incitar la convivencia, el encuentro, el diálogo, el compartir, el contacto, la relación con la naturaleza, el acercamiento, en una idea, para comunicarnos y humanizarnos.

3 Declaración de Rosario por el derecho a la ciudad (1992: 1). 


\section{La comunicación urbana como negocio}

Esta dinámica de la expansión del capital a todas las áreas de la vida ha introducido en nuestras estructuras mentales de países en vías de crecimiento, la concepción mercantilista de que, por encima de todo, la comunicación urbana debe ser un negocio. En consecuencia, ha ocasionado que los espacios de comunicación pública se privaticen para convertirlos en zonas de lucrativas ganancias económicas.

Así, con la introducción en América Latina de la ideología neoliberal del mercado que postula el "dejar hacer, dejar pasar", cada vez más, la zonas de lo público se han privatizado-comercializado para hacerlas modernas. De esta forma, el mercado define más el sentido, la dinámica y la forma de las ciudades y no las necesidades mayoritarias del desarrollo social. Con ello, el espacio de encuentro público crecientemente se convierte en un ámbito comercial, como sucede con los mall, los centros comerciales, los supermercados, etcétera, y no como un espacio de reencuentro con lo público.

\section{El surgimiento de la video-vida}

Dentro de tendencia urbano-mercantil que ha seguido el proceso de producción y reproducción de las sociedades latinoaméricanas se ha difundido rápidamente la mentalidad de que para que todo espacio público de comunicación sea moderno, debe de estar atravesado por el complejo audiovisual, pues de lo contrario será atrasado o anacrónico. Así, ha surgido en las principales ciudades de América Latina la "video-vida" como fenómeno cultural que ha atravesado todas las actividades de nuestra existencia.

\section{El derrumbe de las relaciones humanas}

Derivado de los procesos de modernización industrial y de las crisis urbanas en las ciudades latinoamericanas, especialmente en las mas "desarrolladas", se ha producido un derrumbe de las relaciones humanas de comunión y un debilitamiento de los canales interpersonales de comunicación, generando una fuerte erosión de la relación social más fundamental que es el encuentro personal con los otros.

Así, observamos que el ritmo de sobrevivencia urbana nos ha llevado a sustituir cada vez más a nuestra familia sanguínea de origen por los lazos de una débil familia 
ampliada proveniente del mundo del trabajo. Que cada vez más el nivel de aislamiento humano que se incrementa, en las ciudades ha provocado que vía los anuncios oportunos de los principales periódicos y revistas aparezcan solicitudes de personas que expresan sus medidas corporales, características físicas, modos de pensar, datos personales, etcétera, para buscar "amigos", "esposos" o "compañeros" que mitiguen su soledad. Que cada vez más tenemos en las metrópolis menos parques, jardines, banquitas, rinconcitos, calles empedradas, fuentes, etcétera, donde podamos dialogar para descubrirnos los unos a los otros, y estas son sustituidas por carpetas de asfalto, avenidas de cemento y ejes viales para los automóviles. Que cada vez más la relación elemental del juego corporal entre padres e hijos que se daba mediante el retozo en las generaciones anteriores, es ahora crecientemente substituida por la vinculación electrónica que se da entre éstos a través de la pantalla con el Nintendo, el Atari y las nuevas generaciones de video juegos que se introducen con las modernas tecnologías de información. Que cada vez más nuestros ancianos estorban al mundo moderno del "progreso urbano" al ya no ser eficientes o productivos, y por consiguiente, son intensivamente abandonados frente al televisor o en los asilos. Que cada vez más las personas comunes y corrientes de esta generación morimos más solos en los panteones, pues la vida "desarrollada" y "productiva" de las urbes modernas ya no nos da tiempo para acompañar a nuestros muertos a su último adiós, etcétera.

En este sentido, observamos que "mientras más grande es una ciudad, se vuelve más fragmentada, compleja e incomunicada, dificultando el encuentroentre amigos y familiares. La familia misma pierde hoy su poder de convocatoria y se refuerza en su núcleo central: padres e hijos, manteniéndose estos últimos hasta la edad de separación. Así, se diseña en las ciudades latinoamericanas la familia-individuo que deja de ver y visitar a los otros miembros - abuelos, tíos, primos, etcétera y a otros amigos queridos. Las grandes distancias, las dificultades del transporte, el cansancio y el agotamiento de la jornada diaria en el trabajo o en el estudio ayudan a aumentar la necesidad de aislamiento en una casa o en un pequeño apartamento de concentraciones de edificios donde se atrinchera hoy la clase media, la popular y buena parte de la alta con una inmensa antena parabólica como modelo de la vida urbana" (Silva, 1993: 26).

De igual forma, constatamos que los "especialistas de la comunicación" para reproducir profesionalmente en las escuelas de información a los nuevos cuadros que dirigirán el futuro de esta realidad urbana, construimos currículos académicos 
que estudian la teoría de mercado, las campañas políticas, las culturas populares, las nuevas tecnologías, los métodos de investigación, las técnicas publicitarias, la producción de contenidos televisivos, los lenguajes de la radio, la estética cinematográfica, la información en el siglo XXI, las herramientas semiológicas, la realidad virtual, etcétera; pero nunca abordamos el proceso humano de la comunicación especialmente interpersonal, que es la base central de donde parte y en donde aterriza todo el fenómeno anterior.

\section{La tecnificación de la comunicación}

No obstante el peso dramático de esta realidad sobre la vida urbana, los "comunicólogos profesionales" no nos hemos sensibilizado hacia la necesidad de construir otras formas de comunicación más humanas, y siguiendo los marcos de la modernidad, permanentemente planteamos que lo importante de nuestro campo de actividad es comunicarnos a través de las tecnologías de información. Así, constantemente promovemos la adquisición de más redes de comunicación celulares, ordenadores autoprogramables, más servicios de cable a domicilio, pantallas estereofónicas, televisiones de alta definición, walkman con ecualizadores, teletextos, reproductores de compact disks, teléfonos celulares, radio localizadores automáticos, etcétera, y no el simple hecho de escucharnos y acercarnos para conocernos e impulsarnos como seres humanos.

\section{La videocomunicación}

Sin embargo, ante esta realidad de profunda regresión humana que se presenta en nuestra sociedad, en los pocos espacios de diálogo, reunión y encuentro personal que quedan en nuestras deshumanizadas urbes, la propuesta modernizante de los "comunicadores profesionales" ha sido dar el tiro de gracia a estos resquicios de vida para convertirlos en zonas de pasatiempo posmodernas. Así, hemos transformado la taquería en "video taco", el bar en "video bar", la pizzería en "video pizza", la discoteque en "video discoteque", el restaurante en "video goumete", la sala de espera en "video sala", el camión en "video bus", el metro en "video metro", el avión en "aéreo video", la caseta telefónica en "video teléfono", - sólo falta el "video sanitario" que no debe tardar en surgir - propiciando una vez más la 
distancia y el desencuentro entre las personas con su consecuente estado de creciente oscuridad humana.

Incluso, esta concepción "moderna de la comunicación" ha avanzado tanto, que por ejemplo, en México, algunos de los principales jardines del Distrito Federal se han convertido en video jardines para ver a través de pantallas gigantes de televisión eventos como la pelea del boxeador "Macho" Camacho, el concurso Señorita México, los debates políticos entre los diversos candidatos a la Presidencia de la república, los informes presidenciales, los campeonatos de fútbol, etcétera, restándoles su carácter de zonas de tranquilidad y de armonía con la naturaleza.

De esta forma, la relación con el complejo del video en las ciudades sustituye el espacio de encuentro y contacto de la plaza pública, del jardín, de la alameda, del quiosco, etcétera, produciendo la "video-vida".

Paradójicamente, intentando producir dinámicas de comunicación con todo el arsenal de tecnologías informativas con que contamos al terminar este siglo, esta práctica urbana posmoderna, ha transformado progresivamente dichos espacios, y otros más, en áreas de incomunicación humana, al suprimirles su ambiente de privacía y de individuación que le son propios, para convertirlos en otros aparatos más de la ideologización del dinero y del poder.

\section{La reproducción espiritual urbana vía los medios de comunicación}

Considerando la dinámica de existencia moderna, observamos que el ciclo de la vida cotidiana de la población latinoamericana en las ciudades tiene cuatro fases: La primera es la fase del sueño, donde los individuos recuperamos todas las energías físicas perdidas durante la jornada laboral para poderlas volver a invertir al día siguiente en la esfera de la producción. La segunda, la fase del trabajo, donde lo único que cuenta es que se realice la lógica de la producción, y por lo tanto lo más importante que hay que hacer es ser eficiente. La tercera, la fase de la reproducción de la infraestructura cotidiana de vida, donde lo que hay que efectuar es el arreglo del hogar, la compra de los alimentos, la realización de los servicios básicos de la vida cotidiana, para sobrevivir. Y la cuarta, la fase del esparcimiento, donde está el único espacio que tenemos los latinoamericanos para descansar mentalmente, esto es, para vivir el placer. Es decir, para re-invertarnos como seres humanos, o lo que es igual, para re-crearnos de manera distinta, para dejar de repetirnos en 
el terreno de la producción económica, todolo cual significa, imaginarnos a nosotros mismos de manera nueva y crecer.

En esta última etapa debido a la existencia, cada vez más adversa del contexto urbano latinoamericano, pues se han reducido drásticamente los espacios de áreas verdes en las metrópolis, se ha estrechado el tamaño de la vivienda, se ha incrementado la inseguridad de las ciudades para salir a pasear y se han aumentado los costos del esparcimiento extra-hogareño; los habitantes citadinos de América Latina crecientemente tendemos a canalizar el tiempo de nuestro esparcimiento dentro del complejo audiovisual que ofrece la televisión. Así, vemos que, cada vez más, los latinoamericanos urbanos estamos más expuestos a la televisión y otros medios de comunicación, se incrementa el consumo de video-homes, se eleva el tiempo de exposición a la televisión, y aumenta el porcentaje del juego familiar que cruza por la pantalla a través de los ataris, los nintendo y otros video juegos.

Todo ello, significa en última instancia que cada vez más en las ciudades la reproducción espiritual de los individuos, es decir, el horizonte de imaginación desde donde se reinventan, proviene de los medios de información, especialmente de la televisión y no de otras fuentes culturales.

\section{El hombre ausente del estudio de} los procesos de comunicación urbanos

Ante este panorama, podemos decir que para el modelo central de comunicación urbana que hemos construido en estos años en América Latina, todo ha sido importante de considerar excepto nosotros como seres humanos. Es decir, nosotros no hemos sido importantes para nosotros mismos, pues no hemos colocado al fenómeno humano en el centro de la reflexión, la discusión y la acción comunicativa; sino que nos hemos enredado en el tratamiento y la super valoración de otras mediaciones tecnológicas más sofisticadas, situándolas como el fin último de nuestro quehacer profesional y no como meros apoyos materiales para alcanzar otras metas superiores. Esto es, el sujeto de nuestra comunicación ha sido el manejo de las técnicas informativas y no la transformación de los seres humanos.

Tal parece que el proyecto de comunicación moderna que con toda energía nos hemos esforzado por construir en América Latina, se ha fundado mayoritariamente sobre la negación misma del proceso de comunicación interna del hombre. Es decir, da la impresión de que la relación de comunicación que los "especialistas" 
en esta disciplina hoy producimos entre los individuos, no es aquélla que permite que los hombres se conozcan y profundicen más en sí mismos y en el núcleo social que los rodea; sino al contrario es un mecanismo ajeno impuesto desde afuera de la interioridad más central del hombre, que lo que genera es la oscuridad de los seres.

Por ello, podemos afirmar que la relación que hemos construido con nosotros mismos y con la sociedad a través de la comunicación, especialmente urbana, nos ha llevado a un estado generalizado de incomunicación; y por lo tanto, de pérdida de nosotros mismos como personas, como familia, como barrio, como comunidad, como región y como país. Esto es, la comunicación que hoy practicamos es un mero artificio más sobre la superficie de la sociedad y de nuestras existencias, pues no va al fondo de las necesidades profundas del hombre.

Ante ello nos preguntamos para qué queremos las máquinas de difusión de la quinta generación y los trillones de bits de información que nos ofrece la modernidad; si hoy en las urbes entre los seres humanos nos es progresivamente más difícil comunicarnos de mirada a mirada, de corazón a corazón, de centro a centro. Por ello, podemos afirmar que el saldo gremial que queda después de 70 años de estudio y práctica especializada de la comunicación en América Latina, es que hoy hemos perdido lo más importante por lo meramente secundario y accesorio. Es por ello, que al estar próximos a llegar al siglo XXI podemos decir que nuestra sociedad cuenta con especialistas técnicos, médicos, químicos, administradores, ingenieros, abogados, políticos, etcétera; pero en estricto sentido, no obstante que existimos miles de individuos preparados en el campo de la comunicación, las sociedades latinoamericanas todavía no poseen verdaderos comunicadores. Esto debido a que dichos cuadros profesionales nos dedicamos a ejercer todas las actividades propias del quehacer informativo, excepto a construir las condiciones para que los seres humanos se conozcan a sí mismos, se encuentren, se aproximen, se humanicen y evolucionen hacia etapas superiores del ser.

De aquí, la importancia medular en la actualidad de colaborar urgentemente desde todos los frentes políticos, sociales y mentales a crear otro proyecto de comunicación, de cultura y de espiritualidad urbanas que partan de las necesidades de crecimiento y humanización del hombre, y no de los simples requerimientos dominantes de la voraz y salvaje acumulación económica a nivel planetario a costa de lo que sea. 


\section{Propuestas}

Es por todo ello, que debido al nivel actuảl de deshumanización que han alcanzado la planeación, organización y mantenimiento de las principales ciudades latinoamericanas, que sugerimos la aplicación de las siguientes políticas de desarrollo cultural:

1) Es necesario que el análisis y la transformación de la relación comunicación-ciudad se asuma en su sentido global y sea retomado dentro de las políticas, programas y planes de desarrollo regional de los estados latinoamericanos.

2) Es indispensable que las constituciones legislativas de los estados latinoamericanos incluyan el "Derecho ciudadano a la apropiación a la ciudad" dentro de la declaración de sus garantías individuales mínimas.

3) Es dentro de estas realidades que es necesario que las sociedades civiles de América Latina trabajen por conseguir un Derecho a la comunicación urbana democrática, eficiente, útil y participativa que permita la gestión de la población en el diseño y organización de sus ciudades. Es decir, ejercer el Derecho ciudadano para apropiarse de la cilldad.

4) Dentro de estas políticas, es urgente que las escuelas de comunicación y cultura latinoamericanas incluyan en sus planes de investigación y estudio el examen del fenómeno comunicación-ciudad como un eje central de su trabajo y reflexión, para colaborar desde éstas a producir horizontes urbanos más humanos que los que ahora nos rodean.

Pensamos que con la consideración y aplicación de estas políticas, y otras más, se podrá colaborar en la producción de contextos metropolitanos más humanos que los que ahora nos enmarcan en la región; ya que de no transformar esta tendencia, para el próximo siglo tendremos en América Latina centros urbanos más interrelacionados con la globalización, con más máquinas inteligentes, con más centros de información, con más súper carreteras, etcétera, pero también tendremos conglomerados de ciudades, ecologías e individuos destruidos en proporción geométricamente mayor, a los que ahora conocemos. 


\section{Referencias bibliográficas}

DECLARACIÓN DE ROSARIO POR EL DERECHO A LA CIUDAD (1992): Conclusiones del Seminario Internacional sobre Comunicación y Ciudad, Fundación Solidaridad, Rosario, Provincia de Santa Fe, República de Argentina. 24 al 26 de agosto.

RUBIO ANGULO Jaime (1993): "La ciudad: lugar y símbolo de la comunicación". Signo y Pensamiento Núm. 22, Santafé de Bogotá, Colombia: Facultad de Comunicación Social-Pontificia Universidad Javeriana.

Silva Armando (1993): "Ciudad imaginada". Signo y Pensamiento Núm. 22, Santafé de Bogotá, Colombia: Facultad de Comunicación Social-Pontificia Universidad Javeriana. 